\title{
First characterization of the probiotic potential of lactic acid bacteria isolated from Costa Rican pineapple silages
}

\author{
Jannette Wen Fang Wu Wu ${ }^{1}$, Mauricio Redondo-Solano ${ }^{2}$, Lidieth Uribe ${ }^{3}$, Rodolfo WingChing-Jones ${ }^{4}$, Jessie Usaga \\ 5 , Natalia Barboza ${ }^{\text {Corresp. } 6}$ \\ 1 Food Technology Department, Universidad de Costa Rica, San Pedro, San José, Costa Rica \\ 2 \\ Research Center for Tropical Diseases (CIET) and Food Microbiology Research
Costa Rica (UCR), Universidad de Costa Rica, San Pedro, San José, Costa Rica \\ 3 Agronomic Research Center (CIA), Universidad de Costa Rica, San Pedro, San José, Costa Rica \\ 4 Animal Science Department, Animal Nutrition Research Center (CINA), Universidad de Costa Rica, San Pedro, San José, Costa Rica \\ 5 National Center for Food Science and Technology (CITA), Universidad de Costa Rica, San Pedro, San José, Costa Rica \\ 6 Food Technology Department, National Center for Food Science and Technology (CITA), Center for Research in Cellular and Molecular Biology (CIBCM)., \\ Universidad de Costa Rica, San Pedro, San José, Costa Rica \\ Corresponding Author: Natalia Barboza \\ Email address: natalia.barboza@ucr.ac.cr
}

Background. Agro-industrial waste from tropical environments could be an important source of lactic acid bacteria (LAB) with probiotic potential.

Methods. Twelve LAB isolates were isolated from pineapple silages. The species identification was carried out considering 16S rRNA and pheS genes. Experiments to evaluate the probiotic potential of the isolates included survival under simulated gastrointestinal environment, in vitro antagonistic activity (against Salmonella spp. and Listeria monocytogenes), auto-aggregation assays, antibiotic susceptibility, presence of plasmids, adhesiveness to epithelial cells, and antagonistic activity against Salmonella in HeLa cells.

Results. Lacticaseibacillus paracasei, Lentilactobacillus parafarraginis, Limosilactobacillus fermentum, and Weissella ghanensis were identified. Survival of one of the isolates was $90 \%$ or higher after exposure to acidic conditions ( $\mathrm{pH}: 2$ ), six isolates showed at least $61 \%$ survival after exposure to bile salts. The three most promising isolates, based on survivability tests, showed a strong antagonistic effect against Salmonella. However, only L. paracasei_6714 showed a strong Listeria inhibition pattern; this isolate showed a good auto-aggregation ability, was resistant to some of the tested antibiotics but was not found to harbor plasmids; it also showed a high capacity for adhesion to epithelial cells and prevented the invasion of Salmonella in HeLa cells. After further in vivo evaluations, L. paracasei_6714 may be considered a probiotic candidate for food industry applications and may have promising performance in acidic products due to its origin. 
1 First characterization of the probiotic potential of lactic acid bacteria isolated from Costa

2 Rican pineapple silages

3

4 Jannette Wen Fang Wu Wu${ }^{1}$, Mauricio Redondo-Solano ${ }^{2}$, Lidieth Uribe ${ }^{3}$, Rodolfo WingChing-

5 Jones $^{4}$, Jessie Usaga ${ }^{5}$, Natalia Barboza ${ }^{1,5,6}$

$6 \quad{ }^{1}$ Food Technology Department, University of Costa Rica, San Jose, Costa Rica

$7 \quad 2$ Research Center for Tropical Diseases (CIET) and Food Microbiology Research and Training

8 Laboratory (LIMA), College of Microbiology, University of Costa Rica (UCR), San Jose, Costa

9 Rica

$10{ }^{3}$ Agronomic Research Center (CIA), University of Costa Rica (UCR), San Jose, Costa Rica

$11{ }^{4}$ Animal Science Department, Animal Nutrition Research Center (CINA), University of Costa Rica

12 (UCR), San Jose, Costa Rica

$13{ }^{5}$ National Center for Food Science and Technology (CITA), University of Costa Rica (UCR), San

14 Jose, Costa Rica

$15{ }^{6}$ Center for Research in Cellular and Molecular Biology (CIBCM), University of Costa Rica (UCR),

16 San Jose, Costa Rica

18 Corresponding Author:

19 Natalia Barboza1, 5, 6

20 San Jose, 11501-2060, Costa Rica

21 Email address: natalia.barboza@ucr.ac.cr 


\section{Abstract}

32 Background. Agro-industrial waste from tropical environments could be an important source of 33 lactic acid bacteria ( $L A B)$ with probiotic potential.

34 Methods. Twelve LAB isolates were isolated from pineapple silages. The species identification was carried out considering 16S rRNA and pheS genes. Experiments to evaluate the probiotic potential of the isolates included survival under simulated gastrointestinal environment, in vitro antagonistic activity (against Salmonella spp. and Listeria monocytogenes), auto-aggregation assays, antibiotic susceptibility, presence of plasmids, adhesiveness to epithelial cells, and antagonistic activity against Salmonella in HeLa cells.

Results. Lacticaseibacillus paracasei, Lentilactobacillus parafarraginis, Limosilactobacillus fermentum, and Weissella ghanensis were identified. Survival of one of the isolates was $90 \%$ or higher after exposure to acidic conditions $(\mathrm{pH}: 2)$, six isolates showed at least $61 \%$ survival after exposure to bile salts. The three most promising isolates, based on survivability tests, showed a strong antagonistic effect against Salmonella. However, only L. paracasei_6714 showed a strong Listeria inhibition pattern; this isolate showed a good auto-aggregation ability, was resistant to some of the tested antibiotics but was not found to harbor plasmids; it also showed a high capacity for adhesion to epithelial cells and prevented the invasion of Salmonella in HeLa cells. After further in vivo evaluations, L. paracasei_6714 may be considered a probiotic candidate for food industry applications and may have promising performance in acidic products due to its origin. 
57

\section{Introduction}

59 Currently, the development and intake of functional foods containing probiotic microorganisms

60 have grown considerably due to their known health benefits and ability to prevent certain

61 diseases (Nami et al., 2018). Probiotics are defined by the Food and Agriculture Organization of

62 the United Nations and the World Health Organization (FAO/WHO) as "microorganisms which

63 when administered in adequate amounts confer a health benefit on the host" (FAO/WHO, 2002).

64 Probiotics are capable of enduring gastrointestinal (GI) tract conditions, to temporarily colonize

65 the intestinal environment and supply health effects through modulation of GI microbiota and

66 immunogenic responses, or by producing certain beneficial metabolites of interest (Meybodi \&

67 Mortazavian, 2017; Nami et al., 2018). Delivery of health-promoting microorganisms is

68

69

70

71

72

73

74

75

76

77

78

79

80

81

82

commonly done through the consumption of fermented products, most frequently dairy

(Nascimento et al., 2019). However, with the increased incidence of lactose intolerance, vegetarianism, and other consumer demands, interest in the development of non-dairy probiotic foods has grown. Nevertheless, changes in matrix properties may imply variations in the probiotic physiological dynamics (Dey, 2018).

3 The majority of probiotic bacteria belong to the lactic acid bacteria (LAB) group that are capable to produce antimicrobial compounds such as lactic acid and bacteriocins (Soccol et al., 2010), which makes them suitable as probiotics and bio-control organisms due to their ability to inhibit other microorganisms through the production of different metabolites or by competitive exclusion (Vieco-Saiz et al., 2019).

The genera Lactobacillus and Bifidobacterium are commonly used probiotics. However, Lactococcus, Streptococcus, Enterococcus, and selected yeasts can potentially be used as probiotics as well (de Vrese \& Offick, 2010; Ayala et al., 2019). The selection and characterization of novel microorganisms as potential probiotics must take into account certain properties such as tolerance to low $\mathrm{pH}$ and high bile salt concentrations, as these conditions are 
83 present in the Gl tract environment during digestion processes (García-Ruiz et al., 2014;

84 Byakika et al., 2019). Recent studies have also suggested the importance of evaluating other

85 features such as adhesiveness to the intestinal mucosa, prolonged and stable persistence in the

86 Gl tract, and antimicrobial properties (García-Ruiz et al., 2014).

87 In the last years, probiotics have been obtained mostly from fermented dairy products or the

88 human Gl tract (Kook et al., 2019). Nonetheless, with the increasing demand for novel

89 probiotics with improved health and processing properties, the search for organisms from non-

90 traditional sources has been intensified (Kumar et al., 2015). Some of the unconventional

91 sources that have recently been screened for potential probiotics include traditional fermented

92 foods and beverages, vegetables, and vegetable wastes (Sornplang \& Piyadeatsoontorn, 2016;

93 Ruiz-Rodríguez et al., 2019). Different intrinsic characteristics of these matrices are considered

94 significant factors leading to the diversity of species or isolates that can be found (Sornplang \&

95 Piyadeatsoontorn, 2016). In fact, LAB isolated from non-traditional foods can show better

96 performance and high competitiveness as food additives (Somashekaraiah et al., 2019).

97 Multiple sources to isolate LAB with probiotic potential can be found in tropical and subtropical

environments. In the Latin-American region, different research have been carried out in terms of screening and evaluation of new LAB isolates with health-promoting properties. Most of the studies have focused on the isolation of strains from local foods (Maldonado et al., 2011;

Melgar-Lananne et al., 2013; Ramos, 2013; Agostini et al., 2018), food animals (Iñiguez-

Palomares et al., 2007), and traditional beverages (Romero-Luna et al., 2017). A minor portion of the studies has evaluated strains obtained from environmental sources such as fruits (Veron et al., 2017), rain forest (Benavides, 2016), and agro-industrial products (Schwan et al., 1998;

105 Santos et al., 2016). However, the characterization of LAB with probiotic potential has not been 106 performed in Costa Rica yet.

107 The aim of this research was to assess the probiotic potential of autochthonous LAB isolated 108 from Costa Rican pineapple peel silages. Selected LAB isolates were identified using molecular 
109

110

111

112

113

114

115

116

117

118

119

120

121

122

123

124

125

126

127

128

129

130

131

132

133

markers and subjected to a series of in vitro analyses to evaluate a) resistance to GI tract conditions; b) antimicrobial properties, c) auto-aggregation ability, d) safety properties, and e) adhesion to epithelial cells. These evaluations were done as a preliminary screening for strains with potential application in fermented food applications. This is the first report of the evaluation of LAB with promissory probiotic traits from silages of pineapple residuals from Costa Rica.

\section{Materials \& Methods}

\section{Isolation of Bacterial Isolates}

Lactic acid bacteria were isolated from twenty pineapple peel samples that were vacuumensiled for 30 days. The samples were obtained from a Costa Rican company dedicated to pineapple juice production (WingChing-Jones et al., 2021). Twenty-five grams of each sample was homogenized with $0.1 \%$ w/v peptone water (PW) (Oxoid, Basingstoke, UK) and serially diluted in tubes containing $9 \mathrm{~mL}$ of deionized water. Each dilution was used to streak De Man, Rogosa, and Sharpe agar plates (MRS) (Difco, Le Pont de Claix, France) that were incubated at $35 \pm 2{ }^{\circ} \mathrm{C}$ overnight in anaerobic conditions. Selected colonies were subjected to Gram staining and a posterior morphological identification. The cultures were stored as glycerol stocks (20\% $\mathrm{v} / \mathrm{v}$ ) at $-80{ }^{\circ} \mathrm{C}$ until analyzed. All accessions are kept (with the same name indicated on this research) in the Bacteriology Collection at the Faculty of Microbiology and in the Bacteriology Collection at the National Center for Food Science and Technology (CITA), University of Costa Rica. The strain L. casei ATCC 393 was used as a control given that it is currently commercialized as probiotic (Sidira et al., 2010; Haddaji et al., 2015).

\section{DNA Extraction and PCR Amplification}

Total nucleic acids were extracted from each isolate using a miniprep protocol (Birnboim \& Doly, 1979). A $1.5 \mathrm{~kb}$ fragment of the $16 \mathrm{~S}$ rRNA gene was amplified using the primer pair $27 \mathrm{~F} / 1492 \mathrm{R}$ 
134 (Edwards et al., 1989). The PCR was done considering the conditions of an initial denaturation 135 step at $94{ }^{\circ} \mathrm{C}$ for $1 \mathrm{~min}, 30$ cycles of $94^{\circ} \mathrm{C}$ for $40 \mathrm{~s}, 55^{\circ} \mathrm{C}$ for $1 \mathrm{~min}, 72{ }^{\circ} \mathrm{C}$ for $1 \mathrm{~min}$, and a final 136 extension at $72{ }^{\circ} \mathrm{C}$ for $5 \mathrm{~min}$. The master mix contained a final volume of $25 \mu \mathrm{l}$ and included $1 \mathrm{X}$

137 reaction buffer, $0.2 \mathrm{mM}$ dNTPs, $0.2 \mu \mathrm{M}$ of each primer, $1.5 \mathrm{mM} \mathrm{MgCl}, 1 \mathrm{U}$ Taq DNA

138 polymerase (Bio-Rad, Hercules, CA, USA), and $50 \mathrm{ng}$ of DNA. In addition, a 490 bp fragment 139 of the phenylalanyl-tRNA synthase (pheS) gene was amplified by PCR using the primer pair 140 combination pheS-21-F/pheS-22-R (Naser et al., 2005). The reaction was performed using

141 iProof High-Fidelity DNA polymerase (Bio-Rad) and 50 ng of DNA. The following cycling 142 conditions were used: $98^{\circ} \mathrm{C}$ for $30 \mathrm{~s}, 35$ cycles of $98^{\circ} \mathrm{C}$ for $30 \mathrm{~s}, 60^{\circ} \mathrm{C}$ for $30 \mathrm{~s}$, and $72{ }^{\circ} \mathrm{C}$ for

$14330 \mathrm{~s}$; and a final extension at $72{ }^{\circ} \mathrm{C}$ for $10 \mathrm{~min}$. PCR products were visualized by electrophoresis 144 in a $1 \%$ agarose gel and stained with GelRed (10.000 X) (Biotium, Fremont, CA, USA). The 145 amplified gene fragments were sequenced in both orientations by Macrogen $®$ (Seoul, South 146 Korea).

147

148 Sequencing Analysis

149 The Staden package was used to assemble the obtained sequences. Sequences were aligned 150 using the MUSCLE algorithm (MEGA 7) (Kumar et al., 2016). Sequences were compared with 151 those available in the databases with the BlastN tool (Altschul et al., 1990). Costa Rican 152 sequences were deposited in the GenBank (Table S1). A total of 25 LAB sequences (12 153 isolates from this study and 13 obtained from GenBank) were used for phylogenetic 154 comparison. A region of 1299 nucleotides ( $\mathrm{nt}$ ) corresponding to $16 \mathrm{~S}$ rRNA gene and a fragment 155 of $420 \mathrm{nt}$ for the pheS gene, were selected. A phylogenetic tree was constructed using Bayesian 156 phylogenetic analysis. Ten million generations, eight chains, and a mixed model with sampling 157 every 1.000 generations was considered (Huelsenbeck \& Ronquist, 2001; Ronquist \&

158 Huelsenbeck, 2003). As an external group, the sequences of L. delbrueckeii subsp. lactis KTCT 
1593034 was considered for phylogenetic analysis of both genes. Sequences obtained on this 160 research are shown in bold font.

\section{Assays of Resistance to the Gastrointestinal Tract}

163 Tolerance to $\mathrm{pH}$ 2.0. All isolates and a control strain (L. casei ATCC 393) were exposed to $\mathrm{pH}$ 1642.0 (Ramos et al., 2013), in order to evaluate tolerance to acidic conditions. Each isolate was 165 cultivated in MRS broth (Difco) at $35 \pm 2{ }^{\circ} \mathrm{C}$ for $24 \mathrm{~h}$ and $\mathrm{pH} 7.0$. Cells were centrifuged at 5000 $166 \mathrm{rpm}$ for $5 \mathrm{~min}$ at $24^{\circ} \mathrm{C}$, washed two times in PW (Oxoid), and resuspended in PW (Oxoid) to a 167 concentration of about $10^{8} \mathrm{CFU} / \mathrm{mL}$. A $1 \mathrm{~mL}$ aliquot of the final bacterial suspension was used to 168 inoculate $50 \mathrm{~mL}$ of MRS broth (Difco) adjusted to $\mathrm{pH} 2.0$ using $1 \mathrm{~N} \mathrm{HCl}$ (Thermo Fisher 169 Scientific, Waltham, Massachusetts, USA) and cultures were incubated at $35 \pm 2{ }^{\circ} \mathrm{C}$ for $3 \mathrm{~h}$. 170 After 3 hours of incubation, the effect of acidity was neutralized with $1 \mathrm{~N} \mathrm{NaOH}$ (Thermo Fisher 171 Scientific, Waltham, Massachusetts, USA). To quantify the final bacterial population, $1 \mathrm{~mL}$ 172 aliquots obtained at time 0 and after $3 \mathrm{~h}$ incubation were serially diluted in PW (Oxoid), plated 173 on MRS agar (Difco), and incubated in anaerobic jars for $72 \mathrm{~h}$ at $35 \pm 2{ }^{\circ} \mathrm{C}$. The assay was 174 conducted in triplicate.

175

Lysozyme resistance. Lysozyme resistance was evaluated using a modified version of the method described by Zago et al. (2011). One milliliter of LAB cells and a control strain ( $L$. casei ATCC 393) was cultured in MRS broth (Difco) at $30 \pm 2{ }^{\circ} \mathrm{C}$ for $24 \mathrm{~h}$. After incubation, an aliquot of the culture was centrifuged at $5000 \mathrm{rpm}$ for $5 \mathrm{~min}$ at $24^{\circ} \mathrm{C}$ and washed twice in phosphate buffer (0.1 M, water $\mathrm{pH} 7.0)$. The bottom was resuspended in $2 \mathrm{~mL}$ of Ringer solution ( $8.5 \mathrm{~g} / \mathrm{L}$ $\mathrm{NaCl}, 0.4 \mathrm{~g} / \mathrm{L} \mathrm{KCl}, 0.34 \mathrm{~g} / \mathrm{L}$ hydrated $\mathrm{CaCl}_{2}$ ) (Sigma Aldrich, St. Louis, MO, USA). A sterile electrolyte solution (SES) $\left(0.22 \mathrm{~g} / \mathrm{L} \mathrm{CaCl}_{2}, 6.2 \mathrm{~g} / \mathrm{L} \mathrm{NaCl}, 2.2 \mathrm{~g} / \mathrm{L} \mathrm{KCl}, 1.2 \mathrm{~g} / \mathrm{L} \mathrm{NaHCO}_{3}\right)$ containing $100 \mathrm{mg} / \mathrm{L}$ of lysozyme (Sigma Aldrich) was used to resuspend each LAB (10 $\mathrm{CFU} / \mathrm{mL}$ ). Bacterial suspensions in SES without lysozyme were used as negative controls. Each 
185

186

187

188

189

190

191

192

193

194

195

196

197

198

199

200

201

202

203

204

205

206

207

208

209

210

sample was incubated in a water bath at $37^{\circ} \mathrm{C}$ for 0,30 , and $120 \mathrm{~min}$. After incubation, serial dilutions were made in PW (Oxoid) and samples were plated in duplicate on MRS and incubated for $72 \mathrm{~h}$ at $35^{\circ} \mathrm{C}$ under anaerobic conditions. Cell counts were done, and survival was determined according to the population described as the percentage of CFU/mL after 30 and $120 \mathrm{~min}$ relative to the bacterial population in CFU/mL at time zero. Assays were carried out in triplicate.

Resistance to bile salts. LAB tolerance to bile salts was evaluated following the protocol described by García-Ruiz et al., (2014) with minor modifications. The isolates that showed a survival greater than $20 \%$ after exposure to $\mathrm{pH} 2$ and lysozyme were selected. The isolates were grown overnight in MRS (Difco) and independently inoculated (2\% v/v) in fresh MRS broth (Difco) supplemented with $0.3 \%$ bile salt (w/v) (Sigma-Aldrich). The LAB was incubated in tilted tubes at $35 \pm 2{ }^{\circ} \mathrm{C}$ for $24 \mathrm{~h}$ and shacked at $250 \mathrm{rpm}$ in a rotary benchtop incubated shaker (Lab Companion model SI-600R, Jeio Tech Company, South Korea). Counts were performed following the procedure previously described. A sample without bile salts was used as a control. Every experimental trial was performed in triplicate and the growth percentage of each culture was compared to the control.

\section{Antimicrobial Assays}

Antagonistic activity against pathogens. The antagonistic activity of all isolated LAB isolates and L. casei ATCC 393 against Listeria monocytogenes and Salmonella enterica was evaluated using a modified version of the overlay protocols (Booth et al., 1977; Hütt et al., 2006; Soleimani et al., 2010). Five L. monocytogenes strains were used, including four isolates from processed meat products and one reference strain (ATCC 19116). The five Salmonella isolates used in the study included one Salmonella serovar Typhimurium, one S. Typhi, and three isolates of undefined serotype. Before the experiments, each LAB and pathogen strain was individually 
211 grown at $35.0 \pm 0.5^{\circ} \mathrm{C}$ for $24 \pm 2 \mathrm{~h}$ in MRS (Difco) or Tryptic Soy Broth (TSB) (Oxoid),

212 respectively. After incubation, each LAB was inoculated on MRS agar plates in a thick straight

213 line approximately $7 \mathrm{~cm}$ in length and $0.5 \mathrm{~cm}$ from the edge; streaked plates were incubated

214 under capnophilic conditions at $35.0 \pm 0.5^{\circ} \mathrm{C}$ for $24 \pm 2 \mathrm{~h}$. The MRS plates were then overlaid

215 with approximately $5 \mathrm{ml}$ of Brain Heart Infusion agar (BHI) (Oxoid). After solidification, plates

216 were swabbed with a cocktail suspension prepared with the overnight cultures of each

217 pathogen. Petri dishes were incubated at $35.0 \pm 0.5^{\circ} \mathrm{C}$ for $24 \pm 2 \mathrm{~h}$ under aerobic conditions.

218 The plates were then examined for a clear inhibition zone around the line of each LAB. Clear

219 zones were measured, and inhibitory activity was determined (Pan et al., 2009). Inhibition zones

220 with a diameter larger than $6 \mathrm{~mm}$ were considered a confirmation of strong antagonistic activity.

221

222

Antimicrobial activity of the supernatants. The antimicrobial activity of the cell-free supernatants

223

was determined against the same pathogenic strains by using a previously described protocol

224

with modifications (Lourenço \& Pinto, 2011). The isolate L. paracasei_6714, which showed

225

inhibition zones with a diameter larger than $6 \mathrm{~mm}$ for both pathogens, was cultured in MRS

226

broth (Oxoid) at $35 \pm 0.5^{\circ} \mathrm{C}$ for $24 \pm 2 \mathrm{~h}$. The LAB cultures were centrifuged at 1500 rpm for 15

227

min and the supernatant was decanted and filtered $(0.2 \mu \mathrm{m})$ into sterile test tubes. To avoid an

228

inhibitory effect due to acid lactic exposure, the $\mathrm{pH}$ of the supernatant was adjusted to 7.00 with

229

a solution of $0.1 \mathrm{M} \mathrm{NaOH}$ (Thermo Fisher Scientific, Waltham, Massachusetts, USA) and the

230

supernatant was used immediately. An isolated colony of each pathogenic strain grown

231

overnight on Tryptic Soy Agar (TSA) (Oxoid) was suspended in PW (Oxoid) to obtain a

232

McFarland standard of 0.5 ; equal volumes of each strain suspension were mixed to obtain the cocktail solutions used in the experiments. The wells of a 96-well microplate were filled with a

$50 \mu \mathrm{L}$ of sterile TSB (Oxoid), $50 \mu \mathrm{L}$ of the indicator pathogen solution, and variable volumes (50,

$45,40,35,30,25,20$, and $15 \mu \mathrm{L}$ ) of filtered supernatant adjusted to $50 \mu \mathrm{L}$ with sterile MRS

(Difco). Positive and negative controls were included. The positive control was prepared with 50 
$237 \mu \mathrm{L}$ of sterile TSB (Oxoid), $50 \mu \mathrm{L}$ of the indicator pathogen, and $50 \mu \mathrm{L}$ of sterile MRS (Difco).

238 Negative controls did not contain the pathogen, and the volume was adjusted with $50 \mu \mathrm{L}$ of 239 sterile PW (Oxoid). Microplates were incubated aerobically at $35.0 \pm 0.5^{\circ} \mathrm{C}$ for $24 \pm 2 \mathrm{~h}$ in high 240 humidity conditions and the absorbance at $620 \mathrm{~nm}$ was measured in an Ultra Microplate Reader 241 (Biotek Instruments, Winooski, VT, USA). Results were adjusted by subtracting the absorbance 242 value obtained for the negative control. All determinations were performed in triplicate. To 243 analyze the inhibitory effect of the supernatant solutions on the two pathogens, two-way 244 analysis of variance (ANOVA) followed by Tukey's honest significant difference test were 245 performed using JMP version 11 (SAS Institute Inc., USA). Differences were considered 246 significant at a $P$-value of $<0.05$.

247

248

\section{Auto-aggregation Assays}

249 The auto-aggregation assay was performed following the protocol described by Rastogi et al. 250 (2020) with some modifications. L. paracasei_6714, L. fermentum_6702 and L. casei ATCC 393 251 (control) were grown in MRS broth at $35 \pm 2{ }^{\circ} \mathrm{C}$ for $24 \mathrm{~h}$ and were later harvested through 252 centrifugation $\left(10.000 \times \mathrm{g}\right.$ for $\left.15 \mathrm{~min}, 4^{\circ} \mathrm{C}\right)$, washed twice with phosphate buffer solution (PBS)

253 (50 mM KH2PO4/K2HPO4, pH 6.8) (Sigma-Aldrich, San Luis, Missouri, USA) and resuspended 254 in PBS to obtain an absorbance of around 0.8 at $600 \mathrm{~nm} .3 \mathrm{~mL}$ of bacterial suspension was 255 vortexed and incubated at room temperature for 4 hours. Every hour, $0.1 \mathrm{~mL}$ of upper 256 suspension was transferred to $3.9 \mathrm{~mL}$ of $\mathrm{PBS}$ and the $\mathrm{OD}_{600}$ was measured. PBS was used as 257 blank.

258 The auto-aggregation percentage was then calculated using the equation:

$$
\frac{[A o-A t]}{A o} * 100=\% \text { Cellular Auto - aggregation }
$$

260 Where $A_{t}$ is the $O D_{600}$ at time $t(t=1,2,3,4)$ and $A_{o}$ is the $O D_{600}$ at $t=0$. 
262 Safety Assays

263 Antibiotic resistance. The antibiotic sensitivity of isolate L. paracasei_6714 was evaluated by 264 following the swab and agar disk diffusion method (Hudzicki, 2013). A complete set of 265 antibiotics comprising different families was used. The LAB isolate was cultured in MRS broth 266 (Oxoid) at $35 \pm 0.5^{\circ} \mathrm{C}$ for $24 \pm 2 \mathrm{~h}$ and the suspension of the test isolate was swabbed on 267 solidified Müller-Hinton agar (Oxoid) using a sterile cotton swab. Antibiotic disks impregnated 268 with ciprofloxacin $(5 \mu \mathrm{g})$, vancomycin $(30 \mu \mathrm{g})$, penicillin (10 IU), amoxycillin with clavulanic acid $269(30 \mu \mathrm{g})$, erythromycin $(15 \mu \mathrm{g})$, amikacin $(30 \mu \mathrm{g})$, streptomycin $(10 \mu \mathrm{g})$, tetracycline $(30 \mu \mathrm{g})$ and 270 chloramphenicol $(30 \mu \mathrm{g})$ (Liofilmchem, Vie a Scozia, Italy) were placed on the agar plates. 271 Plates were incubated at $35 \pm 0.5^{\circ} \mathrm{C}$ for $24 \pm 2$ in capnophilic conditions. After incubation, the 272 diameter of the inhibition zones was measured and compared with the standards established by 273 the Clinical and Laboratory Standard Institute (Sharma et al., 2016; Wolupeck et al., 2017). 274 Experimental trials were performed in triplicate.

275

276

Plasmid DNA isolation. L. paracasei_6714 was cultured in MRS broth (Oxoid) at $35 \pm 0.5^{\circ} \mathrm{C}$ for $27724 \pm 2$ h. Plasmid DNA was extracted using a QIAprep Spin Miniprep Kit (Qiagen, Hilde, 278 Germany). The DNA was run and visualized in a $0.8 \%$ agarose gel stained with GelRed® 279 (Biotium, Fremont, CA, USA). Plasmid size was estimated using a using a 100 bp MassRuler 280 DNA ladder (Thermo Fisher Scientific).

281

282 Cell Culture Assays

283 Preparation of cell monolayer. The in-vitro adhesion of L. paracasei_6714 was assayed using 284 HeLa cells (kindly supplied by the Research Center for Tropical Diseases), University of Costa 285 Rica). Cells were cultured in a monolayer of Eagle's Minimum Essential Media (EMEM)

286 (Thermo Fisher Scientific) supplemented with $10 \% \mathrm{v} / \mathrm{v}$ fetal bovine serum, $20 \mu \mathrm{M}$ glutamine per $287 \mathrm{~mL}, 50 \mathrm{U}$ penicillin $\mathrm{G}$, and $50 \mu \mathrm{g} / \mathrm{mL}$ of streptomycin. Cultured cells were incubated at $35 \pm 0.5$ 
$288{ }^{\circ} \mathrm{C}$ in a modified atmosphere of $5 \% \mathrm{CO}_{2}$ and $95 \% \mathrm{O}_{2}$ until used. Before experiments were 289 conducted, the EMEM (Thermo Fisher Scientific) was discarded and cells were washed with 5 $290 \mathrm{~mL}$ of 10X PBS (Sigma-Aldrich). Cells were then covered with a solution of $2.5 \mathrm{~mL}$ of trypsin 291 and EDTA 0.05 (GIBCO, Thermo Fisher Scientific) with phenol red (GIBCO, Thermo Fisher 292 Scientific) and incubated for 3 min to promote cell separation. Detached cells were resuspended 293 in $2.5 \mathrm{ml}$ of EMEM (Thermo Fisher Scientific), and a small volume was obtained for cell 294 quantification using a Neubauer chamber. A 12-well microplate was filled with different volumes 295 of cell suspensions and $2 \mathrm{~mL}$ of EMEM (Thermo Fisher Scientific) to obtain a cell concentration 296 of $10^{6}$ cells $/ \mathrm{ml}$ and then incubated for $48 \mathrm{~h}$, as previously indicated.

297

298

In-vitro cell adhesion assay. A modified version of a previously published methodology was 299 used (Gopal et al., 2001; Tsai et al., 2005). L. paracasei_6714, at a concentration of about 107 300 CFU/mL in EMEM (Thermo Fisher Scientific), was placed over a monolayer of HeLa cells previously grown on a glass slide incubated inside a 12-well microplate. Microplates were then incubated for $2 \mathrm{~h}$ at $35 \pm 0.5^{\circ} \mathrm{C}$. After incubation, cells were washed twice with PBS (SigmaAldrich), fixed with $10 \%$ of paraformaldehyde for 10 min, washed twice with PBS (Sigmaadhesion was evaluated by quantifying the mean number of bacterial cells attached to the HeLa cell monolayer in 5 randomly selected microscopic fields. L. paracasei counts were determined capacity isolate determined in preliminary assays not included here) was included for comparison. 
313 Treatment assay. A modified version of a previous published methodology was used (Giannella 314 et al., 1973). Salmonella serovar Typhimurium was grown on TSB (Oxoid) at $35 \pm 0.5^{\circ} \mathrm{C}$ for 24 $315 \pm 2 \mathrm{~h}$ and diluted in antibiotic-free EMEM to obtain a concentration of about $10^{7} \mathrm{CFU} / \mathrm{mL}$. $L$. 316 paracasei_6714 was grown in MRS (Oxoid) incubated under the same conditions and then 317 diluted as described for Salmonella. A volume of $1 \mathrm{~mL}$ of each culture suspension was added to 318 each cell monolayer inside the 12-well microplate. Plates were centrifuged at $1600 \mathrm{rpm}$ for 5 319 min and then incubated for 0,3 , and $24 \mathrm{~h}$ under the same conditions described for cell 320 maintenance. After incubation, wells were washed two times with PBS and then kept for $1 \mathrm{~h}$ in 321 fresh EMEM (Thermo Fisher Scientific) medium containing $100 \mu \mathrm{g} / \mathrm{mL}$ of gentamicin. After 322 gentamicin exposure, each well was washed twice with PBS (Sigma-Aldrich) and cells were 323 then lysed with ultrapure water for $10 \mathrm{~min}$. Appropriate dilutions in PW (Oxoid) were spread onto 324 TSA (Oxoid) and xylose lysine deoxycholate agar (XLD) (Oxoid). The plates were incubated at $32535 \pm 0.5^{\circ} \mathrm{C}$ overnight. Bacterial counts were used to calculate the invasion rate. A positive 326 control of Salmonella was included. Experiments were performed in triplicate.

Protection assay. The protocol described for the treatment assay was modified to include preexposure of each cell monolayer to L. paracasei_6714 for 3 and 24 h before infection with Salmonella.

\section{Results}

A total of twelve different $L A B$ morphotypes were isolated from twenty pineapple silages with increasing levels of urea. Considering the $16 \mathrm{~S}$ rRNA sequence and pheS gen the isolates correspond to L. paracasei (seven isolates), Lentilactobacillus parafarraginis (two isolates), 335 Limosilactobacillus fermentum (two isolates), and W. ghanensis (one isolate) (Table 1 and 336 Table S1). When the sequences obtained in this research and those selected from GenBank 337 (www.genbank.com) were considered, a clear cluster was established (Fig. 1). Equivalent 
338 length portions of both genes were used to resolve the species groups obtained. The species 339 were renamed according to the novel classification of Zheng et al. (2020). Isolates of $L$.

340 paracasei were also previously characterized with multilocus typing sequences (MTLS). Results 341 were reported by Wing Ching-Jones et al. (2021).

342 After exposure to acidic conditions $(\mathrm{pH} 2.0)$, all $L A B$ isolates were viable, but just one isolate ( $L$. 343 parafarraginis 6719 ) showed a population that survived more than $90 \%$. No reduction was 344 observed in the population of the control samples ( $\mathrm{pH} \mathrm{6.0)}$ as expected (Table 2) and total 345 reduction was observed in the case of the control isolate L. paracasei ATCC 393. A higher rate 346 of survival was also observed for L. paracasei (isolates: 6710 and 6715 ) with values of $52.6 \%$ 347 and $42.9 \%$, and L. fermentum (isolates: 6702 and 6704 ) with values of $31.2 \%$ and $22.1 \%$, 348 respectively. On the other hand, eight isolates showed more than $90 \%$ of survival after $30 \mathrm{~min}$ exposure to lysozyme but just six of them were able to fulfill these criteria after $120 \mathrm{~min}$ of exposure. Among those isolates showing higher resistance to low pH, just isolates 6704 and 6710 had a survivability of more than $90 \%$ to lysozyme after 120 min of exposure. Interestingly, $\min )$. Given that any of the LAB isolates fulfilled the selection criteria, isolates showing higher resistance to both conditions ( $\mathrm{pH}$ and lysozyme) were selected for the bile tolerance test. Survival was lower than $10 \%$ in all the cases, but higher resistance was observed for $L$. parafarraginis $6719(8.8 \%)$ and L. fermentum $6702(2.1 \%)$. Still, tolerance to bile salts was lower for the control strain (L. casei ATCC 393), a commercially available probiotic culture, 358 when compared with the other isolates.

359 The antagonistic activity of the twelve isolates and the control (L. casei ATCC 393) from this 360 study against selected pathogens is shown in Table 3 and Fig. S1. Three isolates produced 361 strong inhibition zones against Salmonella. Nevertheless, when the isolates were evaluated 362 against L. monocytogenes, only one isolate (L. paracasei_6714) produced an inhibition zone 363 with a diameter greater than the reference criteria $(6 \mathrm{~mm})$. According to these results, the 
364 antimicrobial activity of the supernatant of L. paracasei_6714 was evaluated and the results are 365 shown in Table 4. Significant inhibition of Salmonella was observed with $20 \mu \mathrm{L}$ of the 366 supernatant, while up to $50 \mu \mathrm{L}$ were required to obtain the same effect for Listeria.

367 The auto-aggregation ability of L. paracasei_6714, L. fermentum_6702, and L. casei ATCC 393 368 (control) was measured at four consecutive time intervals (1, 2, 3, and 4 hours). The results 369 conveyed in Fig. 2 in which is shown a steady increase in auto-aggregation by the studied 370 isolates. After 4 h, L. fermentum_6702 showed the lowest auto-aggregation percentage, while $L$. 371 casei ATCC 393 and L. paracasei_6714 presented a good auto-aggregation ability, suggesting

372 an effective cell adhesion capacity.

373 The antibiotic susceptibility of L. paracasei_6714 is shown in Table 5. The isolate was resistant

374 to most of the tested compounds. The only exceptions were amoxicillin with clavulanic acid and 375 erythromycin, where an intermediate sensitivity was observed. In addition, the $L$.

376 paracasei_6714 isolate isolated was not found to harbor plasmids, which indicates a low 377 probability of transferring the antibiotic resistance feature (Fig. S2).

378 The results for the adhesion to HeLa cells are found in Table 6. According to the cell counts, the 379 adhesion capacity of L. paracasei_6714 was $200 \%$ higher than that of L. fermentum (control 380 isolate). The enological capacity of the studied isolate to prevent pathogen invasion is shown in 381 Table 7. In the treatment assay, the adhesion of the pathogen was reduced by approximately 11 $382 \%$. On the other hand, in the protection assay, pathogen reduction was between $10 \%$ and 20 $383 \%$.

384

\section{Discussion}

386 Hostile conditions associated with environmental traits of pineapple peel silages, make the LAB 387 isolated from this matrix, important probiotic or with biotechnological potential. Lactobacilli were 388 the most common group found in this research. These results are similar to other reports of $L A B$ 
389 isolated from fermented products (Sáez et al., 2018), particularly from pineapple and pineapple 390 waste (Mardalena \& Erina, 2016; Arshad et al., 2018). This finding is not surprising due to the 391 exceptional genetic diversity of the Lactobacillus genus, which has recently divided into 23 novel 392 genera (De Bruyne et al., 2010; Dicagno et al., 2010; Zheng et al., 2020). On the other hand, 393 many Weissella isolates have been obtained from fermentation processes and characterized as 394 heterofermentative bacteria. In fact, $W$. ghanensis was first isolated from cacao fermentation 395 (De Bruyne et al., 2010).

396 Isolates were further characterized for their probiotic potential to provide favorable effects on the 397 human gut (Pan et al., 2009). Probiotic evaluation of novel strains must include tolerance to the 398 Gl tract, antimicrobial activity, susceptibility to antibiotics, and adhesion to mammalian cells, 399 among others (Byakika et al., 2019). The group of tests for GI tolerance are aimed to evaluate 400 whether the strains are able to survive exposure to acid and enzymes and eventually the transit through the stomach and intestines (Ramos et al., 2013; García-Ruiz et al., 2014; HernándezAlcántara, 2018). In this study, a low tolerance to low pH was observed for most of the isolates, with the exception of L. parafarraginis_6719 which showed the highest survival response (more than $90 \%$ ). It is important to point out the need to evaluate hundreds of strains to select those that can survive acidic environments (Ramos et al., 2013). However, resistance for all the isolates was higher when compared with the control. It is hypothesized that the tolerance to acidic conditions observed in this study may be related to the ensilage process, in which the LAB that survive the last stages were subjected to acidic $\mathrm{pH}$ for a prolonged period of time 409 (Muraro et al., 2021). Besides, these results indicate that some of the isolates may be able to 410 survive the normal gastric environment. It is worth noting that the average $\mathrm{pH}$ during human 411 digestion is around 2.0 - 3.0 with gradients from 1.8 to 4.0 during 2 to $3 \mathrm{~h}$ periods

412 (Maragkoudakis et al., 2006). Also, the high survival of LAB to lysozyme exposure in this study 413 was similar to the results previously reported (García-Ruiz et al., 2014) where survival greater 414 than $80 \%$ were observed for isolates of L. pentosaceus, L. casei, and L. plantarum after 
415 incubation for $120 \mathrm{~min}$; however, survival was around $50 \%$ for some isolates. Lysozyme 416 resistance of $L A B$ has been attributed to the peptidoglycan structure in the bacteria cell wall, the 417 physiological state of cells, and the enzyme concentration in the medium (Cunningham et al., 418 1991; Delfini et al., 2004). The ability to survive in the presence of bile is another important 419 characteristic of potential probiotic strains (García-Ruiz et al., 2014, Hernández-Alcántara et al., 420 2018). In the case of probiotics, it was established that survival limits for bile salts should be 50 $421 \%$ or higher after exposure to a concentration of $0.3 \%$ (Mathara et al., 2008). Using these 422 criteria, any of the isolates in this study (after $\mathrm{pH}$ and lysozyme tests) were classified as bile423 resistant. Still, Bifidobacterium, other Lactobacillus strains, Pediococcus pentosaceus, and 424 some yeasts have been reported as bile resistant according to these criteria (Delgado et al., 425 2008; Jensen et al., 2012; Turchi et al., 2013; García-Ruiz et al., 2014). To obtain accurate 426 colonization of the host GI tract, a high bile tolerance is a desirable characteristic for bacteria aimed to be used as probiotics (Luo et al., 2012; Byakika et al., 2019). In this research, it was found that bile survival is strain-related instead of LAB species-related and these data are in agreement with previous reports (Delgado et al., 2008; Maldonado et al., 2012). Inhibitory activity against foodborne pathogens is a desirable trait for bacteria with probiotic potential (Hütt et al., 2006). Previous reports have shown that some LAB strains are able to inhibit both Gram-positive and Gram-negative bacteria by the secretion of organic acids or other antimicrobial compounds such as bacteriocins (Alakomi et al., 2000; Vieco-Saiz et al., 2019).

434 For example, a strong antimicrobial potential was reported for L. acidophilus NIT against 435 Salmonella Typhimurium, Escherichia coli, and Clostridium difficile (Pan et al., 2009). Similar 436 findings were observed from this study as L. paracasei_6714 was active against both 437 Salmonella and L. monocytogenes. A previous report by Hütt et al. (2006) also found an 438 important level of diversity in the antimicrobial activity of different LAB strains, highlighting the 439 importance of an extensive evaluation of newly isolated strains. 
440 The antimicrobial capacity of L. paracasei_6714 in solid media was further corroborated with the

441 supernatant test. Bacterial metabolites in the medium such as lactic acid, acetic acid, diacetyl,

442 and others may be responsible for the observed inhibitory effect (Çon \& Gökalp, 2000).

443 Inhibition by L. paracasei_6714 was still observed, even though the supernatant was previously

444 neutralized with $\mathrm{NaOH}$. This suggests that other compounds, such as extracellular proteins as

445 bacteriocins, may be responsible for the observed effect. Several lactobacilli species can

446 excrete antimicrobial proteins (Mora-Villalobos et al., 2020). This property is advantageous in

447 terms of host colonization and competition with other bacteria as other microorganisms are

448 inhibited by the excreted metabolites or through competitive exclusion mechanisms based on

449 competition for binding sites and nutrients (Vieco-Saiz et al., 2019). L. paracasei_6714 is able to

450 synthesize extracellular compounds that can inhibit both Salmonella and L. monocytogenes and

451 it may be able to inhibit pathogens during in vivo applications.

452 According to García-Cayuela et al. (2014), auto-aggregation is a probiotic property that allows the

453 organism to form cell aggregates which in turn increases the adhesion of cells to the epithelial

454 lining of the intestine and therefore, allowing better colonization of the probiotic organism in the

455 gut. The percentage of auto-aggregation obtained for L. paracasei_6714 after $4 \mathrm{~h}$ during this study

456 is greater than $48 \%$ (Rastogi et al., 2020), suggesting a good adhesion capability.

457 Concerning susceptibility to antibiotics, an important level of resistance was observed for $L$.

458 paracasei_6714, especially to vancomycin. This antibiotic is considered one of the last resource

459 treatments for multidrug-resistant pathogens, and as a result, this trait is a major concern

460 (Sharma et al., 2016). Previous studies have linked intrinsic resistance to glycopeptides in

461 lactobacilli with the ability to replace the terminal d-alanine residue with d-lactate or d-serine in

462 the muramyl pentapeptide, which prevents vancomycin binding (Sharma et al., 2016). Antibiotic

463 resistance is considered an advantage for probiotic strains as it facilitates the process of host

464 colonization and survival to eventual exposure to antibiotic treatment (Bacha et al., 2010;

465 Sharma et al., 2014). Nevertheless, there may be a risk of transfer of this feature from antibiotic- 
466

467 468 469

470

471

472

473

474

475

476

477

478

479

480

481

482

483

484

485

486

487

488

489

490

resistant strains to foodborne pathogens, since most of the resistance genes are located in gene hotspots along with mobile elements such as plasmids (Oliveira et al., 2017). However, as no plasmids were detected in L. paracasei_6714, the risk for transferring antibiotic resistance traits to other bacteria during in vivo applications should be low.

Finally, the cell culture test was performed to evaluate the ability of L. paracasei_6714 to adhere to intestinal epithelial cells and mucosal surfaces. This is a prerequisite for gut colonization by probiotics (Janković et al., 2012). Colonization and adhesion may be determined by the aggregation of LAB cells (Collado et al., 2007), which is favored by the formation of a film that contributes to the exclusion of pathogens (Gopal et al., 2001; Tsai et al., 2005). Precisely, L. paracasei_6714 showed a significant level of adhesion to HeLa cells associated with a reduced level of cell infection by Salmonella. Likewise, it was found that LAB reduced cell infection by $E$. coli by $31 \%$ to $52 \%$ (García-Ruiz et al., 2014).

\section{Conclusions}

Pineapple has been associated with the presence of diverse groups of LAB such as Lactobacillus and Weisella; these bacteria are adapted to the hostile conditions imposed by the nature of this matrix. As in Costa Rica, pineapple production is one of the most important activities within the agro-industrial sector, it might be possible to find an important diversity of strains with potential biotechnological applications in both, the fresh and/or in the by-products derived from the pineapple industry that are used as silage material or are regarded as a waste.

This is the first study analyzing bacteria with potential probiotic features from Costa Rican sources. The results confirm that agro-industrial by-products, specifically silages, may be an important source of promising LAB strains with a potential probiotic and biotechnological profile. At least one of the isolates (L. paracasei_6714) obtained could be a potential probiotic candidate 
491 based on its in vitro characteristics and behavior. Additional studies, including encapsulation, 492 could improve survival in the $\mathrm{Gl}$ environment. This isolate showed important antagonistic activity 493 against pathogens of public health concern, antibiotic resistance without the presence of 494 plasmids, and a good adhesion pattern in cell cultures. Further studies to assess its potential use 495 as a beneficial culture in the food industry are highly recommended. Additional tests may include, 496 among others, tolerance to sodium chloride, production of bile salt hydrolase, in vivo tests using 497 animal models, experiments to evaluate the behavior of the isolate in different food matrices, and 498 production of exopolysaccharides.

499

500 501 502 503 504

\section{References}

506

\section{Acknowledgments}

This work was supported by the technical assistance of Henry Castro, Arturo Pacheco, Vanny Mora, and María Fernanda Miranda at the Food Microbiology Laboratory and Molecular Biology Laboratory from UCR. Also, the authors acknowledge M.Sc. Marlen Cordero Serrano from CIET for her technical support during the cell culture assays.

Agostini C, Eckert C, Vincenzi A, Machado BL, Jordon BC, Kipper JP, Dullius A, Dullius CH, Lehn DN, Sperotto RA, Pozzobon A, Granada CE, Maciel MJ, Volken de Souza CF. 2018. Characterization of technological and probiotic properties of indigenous Lactobacillus spp. from south Brazil. 3 Biotech 8(11):451 DOI 10.1007/s13205-018-1469-7.

Alakomi HL, Skyttä E, Saarela M, Mattila-Sandholm T, Latva-Kala K and Helander IM. 2000. Lactic acid permeabilizes gram-negative bacteria by disrupting the outer membrane. Applied Environmental Microbiology 66:2001-2005 DOI 10.1128/aem.66.5.2001-2005.2000. Altschul SF, Gish W, Miller W, Lipman DJ. 1990. Basic local alignment search tool. Journal of Molecular Biology 215:403-410 DOI 10.1016/S0022-2836(05)80360-2. 
515 Arshad FA, Mehmood R, Hussain S, Annus-Khan M, Khan MS. 2018. Lactobacilli as

516 probiotics and their isolation from different sources. British Journal of Research 5:43 DOI

$517 \quad 10.21767 / 2394-3718.100043$.

518 Ayala DI, Cook PW, Franco JG, Bugarel M, Kottapalli KR, Loneragan GH, Brashears MM,

519 Nightingale KK. 2019. A systematic approach to identify and characterize the effectiveness

520 and safety of novel probiotic strains to control foodborne pathogens. Frontiers in Microbiology

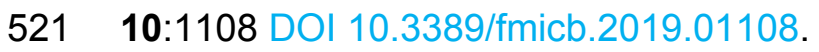

522 Bacha K, Mehari T, Ashenafi M. 2010. Antimicrobial susceptibility patterns of LAB isolated

523 from Wakalim, a traditional Ethiopian fermented beef sausage. Journal of Food Safety 30:213-

524223 DOI 10.1111/j.1745-4565.2009.00201.x.

525 Birnboim HC, Doly J. 1979. A rapid alkaline extraction procedure for screening recombinant 526 plasmid DNA. Nucleic Acids Research 7:1513-23 DOI 10.1093/nar/7.6.1513.

527 Booth SJ, Johnson JL, Wilkins TD. 1977. Bacteriocin production by strains of Bacteroides

528 isolated from human feces and the role of these strains in the bacterial ecology of the colon.

529 Antimicrobial Agents Chemotherapy 11:718-724 DOI 10.1128/aac.11.4.718.

530 Byakika S, Mukisa IM, Byaruhanga YB, Muyanja C. 2019. A Review of criteria and methods

531 for evaluating the probiotic potential of microorganisms. Food Reviews International 35:427-466

532 DOI 10.1080/87559129.2019.1584815.

533 Collado M, Meriluoto J, Salminen S. 2007. Adhesion and aggregation properties of probiotic

534 and pathogen strains. European Food Research Technology 226:1065-1073 DOI

535 10.1007/s00217-007-0632-x.

536 Çon AH, Gökalp HY. 2000. Production of bacteriocin-like metabolites by lactic acid cultures 537 isolated from sucuk samples. Meat Science 55:89-96. DOI 10.1016/S0309-1740(99)00129-1

538 Cunningham F, Proctor V, Goestsh S. 1991. Egg-white lyzozyme as a food preservative: an 539 overview. Worlds Poultry Science Journal 47:141-163. 
540 De Bruyne K, Camu N, De Vuyst L, Vandamme P. 2010. Weissella fabaria sp. nov., from a

541 Ghanaian cocoa fermentation. International Journal of Systematic and Evolutionary

542 Microbiology 60:1999-2005 DOl 10.1099/ijs.0.019323-0.

543 de Vrese M and Offick B. 2010. Probiotics and prebiotics: effects on diarrhea. In: Watson R

544 and Preedy V, eds. Bioactive Foods in Promoting Health: Probiotics and Prebiotics. Academic

545 Press, London, pp.205-227

546 Delfini C, Cersosimo M, Del Prete V, Strano M, Gaetano G, Pagliara A, Ambrò S. 2004.

547 Resistance screening essay of wine lactic acid bacteria on lysozyme: efficacy of lysozyme in

548 unclarified grape musts. Journal of Agricultural and Food Chemistry 52:1861-1866 DOI

549 10.1021/jf034824m.

550 Delgado R, O'Sullivan E, Fitzgerald G, Mayo B. 2008. In vitro evaluation of the probiotic of

551 human intestinal Bifidobacterium species and selection of new probiotic candidates. Journal of

552 Applied Microbiology 104:1119-1127 DOI 10.1111/j.1365-2672.2007.03642.x.

553 Dey G. 2018. Non-dairy probiotic foods: innovation and market trends. In: Panda SK and Shetty

$554 \mathrm{PH}$, eds. Innovations in technologies for fermented food and beverage industries, Springer

555 International Publishing, Cham. pp. 1-339

556 Di Cagno R, Cardinali G, Minervini G, Antonielli L, Rizzello CG, Ricciuti P, Gobbetti M.

557 (2010). Taxonomic structure of the yeasts and lactic acid bacteria microbiota of pineapple

558 (Ananas comosus L. Merr.) and use of autochthonous starters for minimally processing. Food

559 Microbiology 27:381-389 DOI 10.1016/j.fm.2009.11.012.

560 García-Cayuela TK, Ahmed M, Bustos I, de Cadinanos G, Requena T, Peláez C, Martínez-

561 Cuesta MC. 2014. Adhesion abilities of dairy Lactobacillus plantarum strains showing an

562 aggregation phenotype. Food Research International 57:44-50. DOI

563 10.1016/j.foodres.2014.01.010. 
564

565

566

567

568

569

570

571

572

573

574

575

576

577

578

579

580

581

582

583

584

585

586

587

588

\section{García-Ruiz A, González de Llano D, Esteban-Fernández A, Requena T, Bartolomé B,} Moreno-Arribas MV. 2014. Assessment of probiotic properties in lactic acid bacteria isolated from wine. Food Microbiology 44: 220-225 DOl 10.1016/j.fm.2014.06.015.

Giannella RA, Washington O, Gemski P, Formal SB. 1973. Invasion of HeLa cells by Salmonella typhimurium: A model for study of invasiveness of Salmonella. Journal of Infectious Disease 128:69-75 DOI 10.1093/infdis/128.1.69.

Edwards U, Rogall T, Blöker H, Emde M and Bötter E. 1989. Isolation and direct complete nucleotide determination of entire genes. Characterization of a gene coding for $16 \mathrm{~S}$ ribosomal RNA. Nucleic Acids Research 17:7843-7853 DOI 10.1093/nar/17.19.7843.

FAO/WHO. 2002. Probiotics in food. Health and nutritional properties and guidelines for evaluation. Food and Agriculture Organization of the United Nations and World Health Organization, Rome. FAO food and nutrition paper no. 85

Gopal PK, Prasad J, Smart J, Gill HS. 2001. In vitro adherence properties of Lactobacillus rhamnosus DR20 and Bifidobacterium lactis DR10 strains and their antagonistic activity against an enterotoxigenic Escherichia coli. International Journal of Food Microbiology 67:207-216 DOI 10.1016/s0168-1605(01)00440-8.

Haddaji N, Mahdhi AK, Krifi B, Ismail MB, Bakhrouf A. (2015). Change in cell surface properties of Lactobacillus casei under heat shock treatment. FEMS Microbiology Letters 362:17. DOI 10.1093/femsle/fnv047.

Hernández-Alcántara AM, Wacher C, Llamas MG, López P and Pérez-Chabela ML. 2018.

Probiotic properties and stress response of thermotolerant lactic acid bacteria isolated from cooked meat products. LWT - Food Science Technology 91:249-257 DOI

\subsection{6/j.Iwt.2017.12.063.}

Huelsenbeck JP and Ronquist F. (2001). MRBAYES: Bayesian inference of phylogenetic trees. Bioinformatics 17:754-755 DOI 10.1016/j.foodres.2017.07.077. 
589 Hudzicki J. 2013. Kirby-Bauer disk diffusion susceptibility test protocol. American Society of 590 Microbiology 1-25.

591 Hütt P, Shchepetova J, Lõivukene K, Kullisaar T, Mikelsaar M. 2006. Antagonistic activity of 592 probiotic lactobacilli and bifidobacteria against entero- and uropathogens. Journal of Applied 593 Microbiology 100:1324-1332 DOI 10.1111/j.1365-2672.2006.02857.x.

594 Iñiguez-Palomares C, Pérez-Morales R, Acedo-Félix E. 2007. Evaluation of probiotic 595 properties in Lactobacillus isolated from small intestine of piglets. Microbiología 49(3-4):46-54.

596 Janković T, Frece J, Abram M, Gobin I. 2012. Aggregation ability of potential probiotic 597 Lactobacillus plantarum strains. International Journal of Sanitary Engineering Research 6:1959824.

599 Jensen H, Grimmer S, Naterstad K, Axelsson L. 2012. In vitro testing of commercial and 600 potential probiotic lactic acid bacteria. International Journal Food Microbiology 153:216-222 601 DOI 10.1016/j.jijfoodmicro.2011.11.020.

602 Kook SY, Chung EC, Lee Y, Lee D, Kim S. 2019. Isolation and characterization of five novel 603 probiotic strains from Korean infant and children faeces. PLoS One 14:e0223913 DOI 604 10.1371/journal.pone.0223913.

605 Kumar H, Salminen S, Verhagen H, Rowland I, Heimbach J, Bañares S, Young T, Nomoto 606 K, Lalonde M. 2015. Novel probiotics and prebiotics: road to the market. Current Opinion 607 Biotechnology 32:99-103 DOI 10.1016/j.copbio.2014.11.021.

608 Kumar S, Stecher G, Tamura K. 2016. MEGA7: Molecular Evolutionary Genetics Analysis 609 Version 7.0 for bigger datasets. Molecular Biology and Evolution 33:1870-1874 DOI 610 10.1093/molbev/msw054.

611 Lourenço FR, Pinto T. 2011. Antibiotic microbial assay using kinetic-reading microplate 612 system. Brazilian Journal of Pharmaceutical Sciences 47:573-584 DOI 10.1590/S198461382502011000300015. 
614 Luo Y, Ma B, Zou L, Cai YH, Kang JP, Li B, Gao XH, Wang P, Xiao JJ. 2012. Identification

615 and characterization of lactic acid bacteria from forest musk deer feces. African Journal of

616 Microbiology Research 6:5871-5881 DOI:10.5897/AJMR12.807.

617 Maldonado N, Ruiz C, Otero M, Sesma F, Nader-Macías ME. 2012. Lactic acid bacteria

618 isolated from young calves-- characterization and potential as probiotic. Research Veterinary

619 Science 92:342-349 DOI 10.1016/j.rvsc.2011.03.017.

620 Maragkoudakis PA, Zoumpopoulou G, Miaris C, Kalantzopoulos G, Pot B, Tsakalidou E.

621 2006. Probiotic potential of Lactobacillus strains isolated from dairy products. International Dairy

622 Journal 16:189-199 DOI 10.1016/j.idairyj.2005.02.009.

623 Mardalena SS, Erina S. 2016. Molecular characteristics and identification of lactic acid bacteria

624 of pineapple waste as probiotics candidates for ruminants. Pakistan Journal of Nutrition 15:519-

625523 DOI 10.3923/pjn.2016.519.523.

626 Mathara JM, Schillinger U, Guigas C, Franz C, Kutima PM, Mbugua SK, Shin HK,

627 Holzapfel WH. 2008. Functional characteristics of Lactobacillus spp. from traditional Maasai

628 fermented milk products in Kenya. International Journal of Food Microbiology 126:57-64 DOI

629 10.1016/j.jjfoodmicro.2008.04.027.

630 Melgar-Lalanne G, Rivera-Espinoza Y, Reyes Méndez Al, Hernández-Sánchez H. 2013. In

631 vitro evaluation of the probiotic potential of halotolerant Lactobacilli isolated from a ripened

632 tropical Mexican cheese. Probiotics Antimicrobial Proteins 5(4):239-51 DOI 10.1007/s12602-

633 013-9144-0.

634 Meybodi N, Mortazavian A. 2017. Probiotic supplements and food products: a comparative

635 approach. Biochemical Pharmacology 06:227.

636 Mora-Villalobos JA, Montero-Zamora J, Barboza N, Rojas-Garbanzo C, Usaga J,

637 Redondo-Solano M, Schroedter L, Olszewska-Widdrat A, López-Gómez JP. 2020.

638 Multi-product lactic acid bacteria fermentations: A review. Fermentation 6:1-23 DOI

639 10.3390/fermentation6010023.

Peer] reviewing PDF | (2021:05:61126:2:0:NEW 12 Oct 2021) 
640 Muraro GB, de Almeida Carvalho- Estrada P, de Oliveira Pasetti MH, Santos MC, Nussio

641 LG. 2021. Bacterial dynamics of sugarcane silage in the tropics. Environmental Microbiology

642 DOI 10.1111/1462-2920.15428.

643 Nami Y, Haghshenas B, Vaseghi Bakhshayesh R, Jalaly HM, Eslami S, Hejazi MA. 2018.

644 Novel autochthonous lactobacilli with probiotic aptitudes as a main starter culture for probiotic

645 fermented milk. Lwt. 98:85-93 DOI 10.1016/j.Iwt.2018.08.035.

646 Nascimento LCS, Casarotti SN, Todorov SD, Penna ALB. 2019. Probiotic potential and 647 safety of enterococci strains. Annals of Microbiology 69:241-252 DOI 10.1007/s13213-018$648 \quad 1412-5$.

649 Naser SM, Thompson FL, Hoste B, Gevers D, Dawyndt P, Vancanneyt M, Swings J. 2005.

650 Application of multilocus sequence analysis (MLSA) for rapid identification of Enterococcus 651 species based on rpoA and pheS genes. Microbiology 151:2141-2150 DOI

652 10.1099/mic.0.27840-0.

653 Oliveira PH, Touchon M, Cury J, Rocha EPC. 2017. The chromosomal organization of 654 horizontal gene transfer in bacteria. Nature Communications 8:1-11.

655 Pan X, Chen F, Wu T, Tang H, Zhao Z. 2009. The acid, bile tolerance and antimicrobial 656 property of Lactobacillus acidophilus NIT. Food Control 20:598-602 DOI

657 10.1016/j.foodcont.2008.08.019.

658 Rastogi S, Mittal V, Singh A. 2020. In vitro evaluation of probiotic potential and safety

659 assessment of Lactobacillus mucosae strains isolated from donkey's lactation. Probiotics and 660 Antimicrobial Proteins. 12:1045-1056. DOl 10.1007/s12602-019-09610-0.

661 Ramos CL, Thorsen L, Schwan RF, Jespersen L. 2013. Strain-specific probiotics properties of 662 Lactobacillus fermentum, Lactobacillus plantarum and Lactobacillus brevis isolates from 663 Brazilian food products. Food Microbiology 36:22-29 DOI 10.1016/j.fm.2013.03.010. 
664 Romero-Luna HE, Hernández-Sánchez H, Dávila-Ortiz, G. 2017. Traditional fermented 665 beverages from Mexico as a potential probiotic source. Annals of Microbiology 67:577-586 DOI 666 10.1007/s13213-017-1290-2.

667 Ruiz-Rodríguez LG, Mohamed F, Bleckwedel J, Medina R, De Vuyst L, Hebert EM, Mozzi 668 F. 2019. Diversity and functional properties of lactic acid bacteria isolated from wild fruits and 669 flowers present in northern Argentina. Frontiers in Microbiology 10:1091 DOI 670 10.3389/fmicb.2019.01091.

671 Ronquist F, Huelsenbeck JP. 2003. MrBayes 3: Bayesian phylogenetic inference under mixed 672 models. Bioinformatics 19:1572-1574 DOI 10.1093/bioinformatics/btg180.

673 Sáez GD, Flomenbaum L, Zárate G. 2018. Lactic acid bacteria from Argentinean fermented 674 foods: Isolation and characterization for their potential use as starters for fermentation of 675 vegetables. Food Technology Biotechnology 56:398-410 DOI 10.17113/ftb.56.03.18.5631.

676 Santos TT, Ornellas RMS, Arcucio LB, Oliveira MM, Nicoli JR, Dias CV, Trovatti AP, 677 Vinderola CG. 2016. Characterization of lactobacilli strains derived from cocoa fermentation in 678 the south of Bahia for the development of probiotic cultures. LWT-Food Science and 679 Technology 73:259-266 DOI 10.1016/j.Iwt.2016.06.003.

680 Schwan RF. 1998. Cocoa fermentations conducted with a defined microbial cocktail inoculum. 681 Applied Environmental Microbiology. 64:1477-83. DOI 10.1128/AEM.64.4.1477-1483.1998. 682 Sharma P, Tomar SK, Goswami P, Sangwan V, Singh R. 2014. Antibiotic resistance among 683 commercially available probiotics. Food Research International 57:176-195 DOI

684 10.1016/j.foodres.2014.01.025.

685 Sharma P, Tomar SK, Sangwan V, Goswami P, Singh R. 2016. Antibiotic resistance of 686 Lactobacillus sp. isolated from commercial probiotic preparations. Journal of Food Safety 687 36:38-51 DOI 10.1111/jfs.12211.

688 Sidira M, Galanis A, Ypsilantis P, Karapetsas A, Progaki Z, Simopoulo C, Kourkoutas Y. 689 2010. Effect of probiotic-fermented milk administration on gastrointestinal survival 
690 of Lactobacillus casei ATCC 393 and modulation of intestinal microbial flora. Journal of

691 Molecular Microbiology and Biotechnology 19: 224-230. DOI 10.1159/000321115.

692 Soccol CR, Vandenberghe LPS, Spier MR, Medeiros ABP, Yamaguishi CT, De Dea

693 Lindner J, Pandey A, Thomaz-Soccol V. 2010. The potential of probiotics: A review. Food

694 Technology Biotechnology 48:413-434.9.

695 Soleimani NA, Kermanshahi RK, Yakhchali B, Sattari TN. 2010. Antagonistic activity of 696 probiotic lactobacilli against Staphylococcus aureus isolated from bovine mastitis. African

697 Journal of Microbiology Research 4:2169-2173

698 Somashekaraiah R, Shruthi B, Deepthi BV, Sreenivasa MY. 2019. Probiotic properties of

699 lactic acid bacteria isolated from neera: a naturally fermenting coconut palm nectar. Frontiers in 700 Microbiology 10 DOI 10.3389/fmicb.2019.01382.

701 Sornplang P, Piyadeatsoontorn S. 2016. Probiotic isolates from unconventional sources: a 702 review. Journal of Animal Science Technology 58:26 DOI 10.1186/s40781-016-0108-2.

703 Tsai CC, Hsih HY, Chiu HH, Lai YY, Liu JH, Yu B, Tsen HY. 2005. Antagonistic activity

704 against Salmonella infection in vitro and in vivo for two Lactobacillus strains from swine and 705 poultry. International Journal of Food Microbiology 102:185-194 DOI

706 10.1016/j.ijfoodmicro.2004.12.014.

707 Turchi B, Mancini S, Fratini F, Pedonese F, Nuvoloni R, Bertelloni F, Ebani VV, Cerri D.

708 2013. Preliminary evaluation of probiotic potential of Lactobacillus plantarum strains isolated

709 from Italian food products. World Journal of Microbiology and Biotechnology 29:1913-1922 DOI

$710 \quad 0.1007 / s 11274-013-1356-7$.

711 Veron HE, Di Risio HD, Isla MI, Torres S. 2017. Isolation and selection of potential probiotic

712 lactic acid bacteria from Opuntia ficus-indica fruits that grow in Northwest Argentina. LWT -

713 Food Science and Technology 84:231-240 DOI 10.1016/j.Iwt.2017.05.058.

714 Vieco-Saiz N, Belguesmia Y, Raspoet R, Auclair E, Gancel F, Kempf I, Drider D. 2019.

715 Benefits and inputs from lactic acid bacteria and their bacteriocins as alternatives to antibiotic 
716 growth promoters during food-animal production. Frontiers in Microbiology 10:57 DOI

717 10.3389/fmicb.2019.00057.

718 WingChing-Jones R, Redondo-Solano M, Usaga J, Uribe L, Barboza N. 2021. Tipificación

719 con secuencias multilocus en Lactobacillus casei procedentes de ensilados de cáscara de piña.

720 Agronomía Mesoamericana. 32:508-522.

721 Wolupeck HL, Morete CA, DallaSanta OR, Luciano FB, Madeira HM, Freitas de Macedo

722 RE. 2017. Methods for the evaluation of antibiotic resistance in Lactobacillus isolated from

723 fermented sausages. Ciência Rural 47:8.

724 Zago M, Fornasari ME, Carminati D, Burns P, Suàrez V, Vinderola G, Reinheimer J, Giraffa

725 G. 2011. Characterization and probiotic potential of Lactobacillus plantarum strains isolated from 726 cheeses. Food Microbiology 28:1033-1040 DOI 10.1016/j.fm.2011.02.009.

727 Zheng J, Wittouck S, Salvetti E, Franz CMAP, Harris HMB, Mattarelli P, O'Toole PW, Pot B,

728 Vandamme P, Walter J, Watanabe K, Wuyts S, Felis GE, Gänzle MG, Lebeer S. 2020. A

729 taxonomic note on the genus Lactobacillus: Description of 23 novel genera, emended

730 description of the genus Lactobacillus Beijerinck 1901, and union of Lactobacillaceae and

731 Leuconostocaceae. International Journal of Systematic and Evolutionary Microbiology 70:2782-

7322858 DOI 10.1099/ijsem.0.004107.

733

734

735

736

737

738

739

740

PeerJ reviewing PDF | (2021:05:61126:2:0:NEW 12 Oct 2021) 
741 Table legends

742 Table 1 Sequence of primers used for identification of lactic acid bacteria (LAB) from this

743 research. Notes. aLocation on the genome of strain L. paracasei ATCC 334 (GenBank accession

744 no. CP000423) of the primers.

745 Table 2 Resistance/tolerance to $\mathrm{pH}$ 2.0, lysozyme and bile salts of lactic acid bacteria (LAB)

746 isolated from pineapple silage. Notes. $N D$, not determined. Mean values $( \pm$ standard deviation,

$747 n=3)$.

748 Table 3 Inhibition halo of Salmonella enterica and Listeria monocytogenes grown on

749 culture media pre-inoculated with different lactic acid bacteria (LAB) isolated from

750 pineapple silage. Notes. + Inhibition zone between 0- and 3-mm diameter (weak), ++ Inhibition

751 zone between 3- and 6-mm diameter (good), +++ Inhibition zone larger than $6 \mathrm{~mm}$ diameter

752 (strong).

753 Table 4 Absorbance values obtained to evaluate the antimicrobial activity of the

754 supernatant of $L$. paracasei_6714 against Salmonella and L. monocytogenes. Notes. Mean

755 values ( \pm standard deviation, $n=3$ ). Values not sharing a common letter represent significantly

756 different values $(P<0.05)$.

757 Table 5 Antibiotic resistance/susceptibility of $L$. paracasei_6714. Notes. Mean values ( \pm 758 standard deviation, $n=3) . R$, resistant. I, intermediate.

759 Table 6 Adhesion of L. paracasei_ 6714 to HeLa cells per microscopic field.

760 Table 7 Antagonistic effects of L. paracasei_6714 on Salmonella Typhimurium invasion of

761 HeLa cells. Notes. Mean values ( \pm standard deviation, $n=3$ ). Values not sharing a common

762 letter represent significantly different values $(P<0.05)$. aPost-inoculation time with Salmonella

763 Typhimurium.

764 Figure legends

765 Figure 1: Phylogeny based on Bayesian analysis and considering the partial sequences 766 of the 16S rRNA gene (1299 nucleotides (nt)) (A) and phenylalanyl-tRNA synthase gene 
767 (pheS) (420 nt) (B) of lactic acid bacteria (LAB) isolated from ensiled pineapple peels.

768 Probabilities are indicated at nodes. As an external group. L. delbrueckeii subsp. lactis KTCT

7693034 was used as an external sequence for both figures. Sequences obtained on this research

770 are shown in bold font.

771 Figure 2: Cellular auto-aggregation ability of selected lactic acid bacteria (LAB) isolated

772 from pineapple waste and comparison with $L$. casei ATCC 393. Data are reported as mean \pm 773 SD.

774

775

SUMPELENTAL MATERIAL

776 Table S1 GenBank accession numbers of 16S rRNA gene and phenylalanyl-tRNA synthase

777 gene (pheS) sequences from lactic acid bacteria (LAB) isolated from pineapple peel silage.

778 Figure S1: Picture of plaques and the observed inhibition halo of $L$. paracasei_6712 and $L$.

779 paracasei_6714 against L. monocytogenes (A, B) and Salmonella sp. (C, D).

780 Fig. S2: Picture of gel red stained agarose gel (0.8 \%) electrophoresis. Gel order: $100 \mathrm{bp}$

781 MassRuler DNA ladder, miniprep of L. paracasei_6714, and miniprep of positive control.

782

783 


\section{Table $\mathbf{1}$ (on next page)}

Sequence of primers used for identification of lactic acid bacteria (LAB) from this research.

aLocation on the genome of strain L. paracasei ATCC 334 (GenBank accession no. CP000423) of the primers. 


\begin{tabular}{|c|c|c|c|}
\hline Primer name & Forward primer $\left(5^{\prime} \rightarrow 3^{\prime}\right)$ & Reverse primer $\left(5^{\prime} \rightarrow 3^{\prime}\right)$ & Location $^{a}$ \\
\hline $27 F / 1492 R$ & AGA GTT TGA TCC TGG CTC AG & ACG GCT ACC TTG TTA CGA CTT & $259513 \ldots 261026$ \\
\hline pheS-21-F/pheS-22-R & CAYCCNGCHCGYGAYATGC & CCWARVCCRAARGCAAARCC & $1670081 \ldots 1670575$ \\
\hline
\end{tabular}

2 Notes.

aLocation on the genome of strain L. paracasei ATCC 334 (GenBank accession no. CP000423) of the primers. 


\section{Table 2 (on next page)}

Resistance/tolerance to $\mathrm{pH} 2.0$, lysozyme and bile salts of lactic acid bacteria (LAB) isolated from pineapple silage.

$N D$, not determined. Mean values ( \pm standard deviation, $n=3$ ). 


\begin{tabular}{|c|c|c|c|c|c|c|c|c|c|c|c|c|c|c|}
\hline \multirow[b]{3}{*}{ LAB strain } & \multirow{2}{*}{\multicolumn{4}{|c|}{ Tolerance to $\mathrm{pH} 2.0$}} & \multicolumn{6}{|c|}{ Resistance to lysozyme } & \multicolumn{4}{|c|}{ Resistant to bile at $0.3 \%$} \\
\hline & & & & & & & $\mathbf{t}_{30}$ & & & 20 & & & & \\
\hline & $\begin{array}{c}\text { Control } \\
\text { (log } \\
\text { CFU/ml) }\end{array}$ & $\begin{array}{c}\text { Initial } \\
\text { population } \\
\text { (log CFU/ml) }\end{array}$ & $\begin{array}{c}\text { Final } \\
\text { population } \\
\text { (log CFU/ml) }\end{array}$ & $\begin{array}{c}\text { Survival } \\
(\%)\end{array}$ & $\begin{array}{l}\text { Control } \\
\text { (log } \\
\text { CFU/ml) }\end{array}$ & $\begin{array}{c}\text { Initial } \\
\text { population } \\
\text { (log } \\
\text { CFU/ml) }\end{array}$ & $\begin{array}{c}\text { Final } \\
\text { population } \\
\text { (log CFU/ml) }\end{array}$ & $\begin{array}{c}\text { Survival } \\
(\%)\end{array}$ & $\begin{array}{c}\text { Final } \\
\text { population } \\
\text { (log CFU/ml) }\end{array}$ & Survival (\%) & $\begin{array}{c}\text { Control } \\
(\text { log } \\
\text { CFU/ml) }\end{array}$ & $\begin{array}{c}\text { Initial } \\
\text { population } \\
\text { (log CFU/ml) }\end{array}$ & $\begin{array}{c}\text { Final } \\
\text { population } \\
\text { (log } \\
\text { CFU/ml) }\end{array}$ & $\begin{array}{c}\text { Survival } \\
(\%)\end{array}$ \\
\hline L. casei ATCC 393 (control) & 8.50 & $8.1 \pm 1.7$ & $0.00 \pm 0$ & $<90 \%$ & 8.25 & $7.39 \pm 0.09$ & $7.59 \pm 0.18$ & $100 \%$ & $8.45 \pm 0.06$ & $100 \%$ & 8.95 & $9.0 \pm 1.2$ & $3.8 \pm 1.1$ & $<50 \%$ \\
\hline L. paracasei_6709 & 6.83 & $6.56 \pm 0.06$ & $2.94 \pm 0.02$ & $<90 \%$ & 8.37 & $8.26 \pm 0.18$ & $8.37 \pm 0.10$ & $100 \%$ & $8.21 \pm 0.14$ & $90.31 \pm 10.7$ & ND & ND & ND & ND \\
\hline L. paracasei_6710 & 6.99 & $6.57 \pm 0.09$ & $6.28 \pm 0.05$ & $<90 \%$ & 7.96 & $7.93 \pm 0.17$ & $7.95 \pm 0.14$ & $100 \%$ & $7.95 \pm 0.16$ & $100 \%$ & 9.61 & $9.2 \pm 0.5$ & $5.5 \pm 0.4$ & $<50 \%$ \\
\hline L. paracasei_6711 & 7.70 & $7.6 \pm 0.7$ & $6.49 \pm 0.06$ & $<90 \%$ & 7.97 & $7.96 \pm 0.16$ & $8.02 \pm 0.16$ & $100 \%$ & $7.86 \pm 0.16$ & $<90 \%$ & ND & ND & ND & ND \\
\hline L. paracasei_6712 & 6.83 & $6.79 \pm 0.01$ & $5.71 \pm 0.02$ & $<90 \%$ & 8.45 & $8.16 \pm 0.05$ & $8.27 \pm 0.07$ & $100 \%$ & $8.49 \pm 0.35$ & $100 \%$ & ND & ND & ND & ND \\
\hline L. paracasei_6713 & 6.18 & $5.99 \pm 0.004$ & $5.27 \pm 0.01$ & $<90 \%$ & 8.02 & $8.12 \pm 0.15$ & $8.15 \pm 0.16$ & $100 \%$ & $8.03 \pm 0.11$ & $<90 \%$ & ND & ND & ND & ND \\
\hline L. paracasei_6714 & 5.92 & $5.69 \pm 0.05$ & $4.55 \pm 0.07$ & $<90 \%$ & 8.13 & $8.40 \pm 0.25$ & $8.23 \pm 0.06$ & $<90 \%$ & $8.30 \pm 0.15$ & $100 \%$ & ND & ND & ND & ND \\
\hline L. paracasei_6715 & 7.04 & $5.98 \pm 0.07$ & $5.6 \pm 0.1$ & $<90 \%$ & 7.72 & $8.27 \pm 0.28$ & $8.08 \pm 0.13$ & $<90 \%$ & $7.93 \pm 0.04$ & $<90 \%$ & 9.76 & $9.6 \pm 0.2$ & $7.1 \pm 0.5$ & $<50 \%$ \\
\hline L. fermentum_6702 & 6.99 & $6.48 \pm 0.02$ & $5.97 \pm 0.03$ & $<90 \%$ & 8.51 & $8.41 \pm 0.06$ & $8.48 \pm 0.32$ & $100 \%$ & $8.29 \pm 0.14$ & $<90 \%$ & 8.30 & $8.3 \pm 0.1$ & $6.5 \pm 0.5$ & $<50 \%$ \\
\hline L. fermentum_6704 & 6.90 & $6.59 \pm 0.02$ & $5.93 \pm 0.04$ & $<90 \%$ & 8.50 & $8.36 \pm 0.16$ & $8.35 \pm 0.20$ & $97.5 \pm 10$ & $8.41 \pm 0.17$ & $100 \%$ & 10.23 & $9.5 \pm 0.6$ & $7.5 \pm 0.5$ & $<50 \%$ \\
\hline L. parafarraginis_6717 & 6.79 & $6.67 \pm 0.01$ & $5.766 \pm 0.004$ & $<90 \%$ & 8.16 & $8.50 \pm 0.01$ & $6.57 \pm 0.02$ & $<90 \%$ & $6.44 \pm 0.01$ & $<90 \%$ & 8.91 & ND & ND & ND \\
\hline L. parafarraginis_6719 & 7.70 & $7.64 \pm 0.01$ & $7.62 \pm 0.01$ & $\begin{array}{c}95.4 \pm \\
2.3\end{array}$ & 8.00 & $7.82 \pm 0.15$ & $7.59 \pm 0.16$ & $<90 \%$ & $6.93 \pm 0.11$ & $<90 \%$ & 9.08 & $9.04 \pm 0.04$ & $8.00 \pm 0.1$ & $<50 \%$ \\
\hline W. ghanensis 6706 & 5.48 & $5.64 \pm 0.06$ & $4.4 \pm 0.1$ & $<90 \%$ & 6.30 & $6.88 \pm 0.18$ & $6.19 \pm 0.24$ & $<90 \%$ & $6.18 \pm 0.03$ & $<90 \%$ & ND & ND & ND & ND \\
\hline
\end{tabular}

1 Notes.

$N D$, not determined. Mean values ( \pm standard deviation, $n=3$ ). 


\section{Table 3 (on next page)}

Inhibition halo of Salmonella enterica and Listeria monocytogenes grown on culture media pre-inoculated with different lactic acid bacteria (LAB) isolated from pineapple silage.

+ Inhibition zone between 0 - and 3-mm diameter (weak), ++ Inhibition zone between 3- and 6-mm diameter (good), +++ Inhibition zone larger than $6 \mathrm{~mm}$ diameter (strong). 


\begin{abstract}
Table 3 Inhibition halo of Salmonella enterica and Listeria monocytogenes grown on culture media pre-inoculated with different LAB strains isolated from pineapple silage.
\end{abstract}

\title{
Strain
}

$$
\text { Halo }
$$

$$
\text { Salmonella }
$$

Listeria

L. paracasei_6709

L. paracasei_6710

L. paracasei_6711

L. paracasei_6712

L. paracasei_6713

L. paracasei_6714

L. paracasei_6715

L. fermentum_6702

L. fermentum_6704

L. parafarraginis_6717

L. parafarraginis_6719

W. ghanensis_6706

L. paracasei ATCC 393
$++$

$+$

$++$

$++$

$+++$

$++$

$+++$

$+$

$++$

$+$

$++$

$++$

$+++$

$+$
$+$

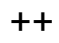

$+$

$++$

$++$

$++$

$+$

$+$

$+$

$++$

$+$

$++$

$+$

1 Notes.

+ Inhibition zone between 0- and 3-mm diameter (weak), ++ Inhibition zone between 3and 6-mm diameter (good), +++ Inhibition zone larger than 6-mm diameter (strong). 


\section{Table 4 (on next page)}

Absorbance values obtained to evaluate the antimicrobial activity of the supernatant of L. paracasei_6714 against Salmonella and L. monocytogenes.

Mean values ( \pm standard deviation, $n=3$ ). Values not sharing a common letter represent significantly different values $(P<0.05)$. 
Table 4 Absorbance values obtained to evaluate the antimicrobial activity of the supernatant of L. paracasei_6714 against Salmonella and L. monocytogenes.

\section{Supernatant volume $(\mu L)$}

$$
0.062 \pm 0.007^{\mathrm{cd}}
$$

$0.09 \pm 0.04^{\mathrm{cd}}$

$0.13 \pm 0.02^{\mathrm{a}}$

40

$0.055 \pm 0.008^{d}$

$0.128 \pm 0.004^{a}$

35

$0.08 \pm 0.03 c^{d}$

$0.14 \pm 0.01^{a}$

30

$0.15 \pm 0.06^{b c d}$

$0.11 \pm 0.05^{\mathrm{ab}}$

25

$0.16 \pm 0.03^{\mathrm{bcd}}$

$0.113 \pm 0.004^{a b}$

20

$0.19 \pm 0.03^{b c}$

$0.129 \pm 0.003^{a}$

15

$0.24 \pm 0.01^{\mathrm{ab}}$

$0.13 \pm 0.01^{a}$

Positive control

$0.151 \pm 0.007^{a}$

\section{Note.}

Mean values ( \pm standard deviation, $n=3$ ). Values not sharing a common letter represent significantly different values $(P<0.05)$. 


\section{Table 5 (on next page)}

Antibiotic resistance/susceptibility of $L$. paracasei_6714.

Mean values ( \pm standard deviation, $n=3$ ). $R$, resistant. I, intermediate. 
Table 5 Antibiotic resistance/suceptibility of $L$. paracasei_6714.

Halo (inhibition zone) Interpretation

$5.3( \pm 0,6) \quad R$

$0.0( \pm 0)$

$\mathrm{R}$

$11.0( \pm 1.0)$

R

$15.0( \pm 0,5)$

I

$15.2( \pm 0,3)$

I

$6.0( \pm 0)$

$\mathrm{R}$

$3.7( \pm 0,6)$

$\mathrm{R}$

$8.8( \pm 1)$

$\mathrm{R}$

$10.3( \pm 0,6)$

R

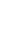

Antibiotic

Ciprofloxacin

Vancomycin

Penicillin

Amoxycilin with clavulanic acid

Eritromycin

Amikacin

Streptomycin

Tetracycline

Chloramphenicol
Notes.

Mean values ( \pm standard deviation, $n=3$ ). $R$, resistant. $I$, intermediate. 
Table 6(on next page)

Adhesion of L. paracasei_6714 to HeLa cells per microscopic field. 
Table 6 Adhesion of $L$. paracasei_6714 to HeLa cells per microscopic field. Strain LAB adherence to epithelial cells

L. paracasei_6714 $403 \pm 18$

L. fermentum_6702

$164 \pm 16$ 


\section{Table 7 (on next page)}

Antagonistic effects of L. paracasei_6714 on Salmonella Typhimurium invasion of HeLa cells.

Mean values ( \pm standard deviation, $n=3$ ). Values not sharing a common letter represent significantly different values $(P<0.05)$. ${ }^{a}$ Post-inoculation time with Salmonella Typhimurium. 


\begin{tabular}{|c|c|c|}
\hline Assays & Log CFU /mL Salmonella & Cell HeLA adhesion (\%) \\
\hline Treatment & $5,3 \pm 0,1^{B}$ & $65 \pm 1^{B}$ \\
\hline Protection $(3 \mathrm{~h})^{\mathrm{a}}$ & $5,4 \pm 0,2^{B}$ & $66 \pm 2^{\mathrm{B}}$ \\
\hline Protection $(24 \mathrm{~h})^{\mathrm{a}}$ & $4,6 \pm 0,1^{c}$ & $56 \pm 1^{c}$ \\
\hline Control & $6,2 \pm 0,1^{A}$ & $76 \pm 2^{A}$ \\
\hline
\end{tabular}

2 Notes.

Mean values ( \pm standard deviation, $n=3$ ). Values not sharing a common letter represent significantly different values $(P<0.05)$. aPost-inoculation time with Salmonella Typhimurium. 
Figure 1

Phylogeny based on Bayesian analysis and considering the partial sequences of the $16 \mathrm{~S}$ rRNA gene (1299 nucleotides (nt)) (A) and phenylalanyl-tRNA synthase gene (pheS) $(420 \mathrm{nt})(\mathrm{B})$ of lactic acid bacteria (LAB) isolated from ensiled pineapple peels.

Probabilities are indicated at nodes. As an external group. L. delbrueckeii subsp. lactis KTCT 3034 was used as an external sequence for both figures. Sequences obtained on this research are shown in bold font. 


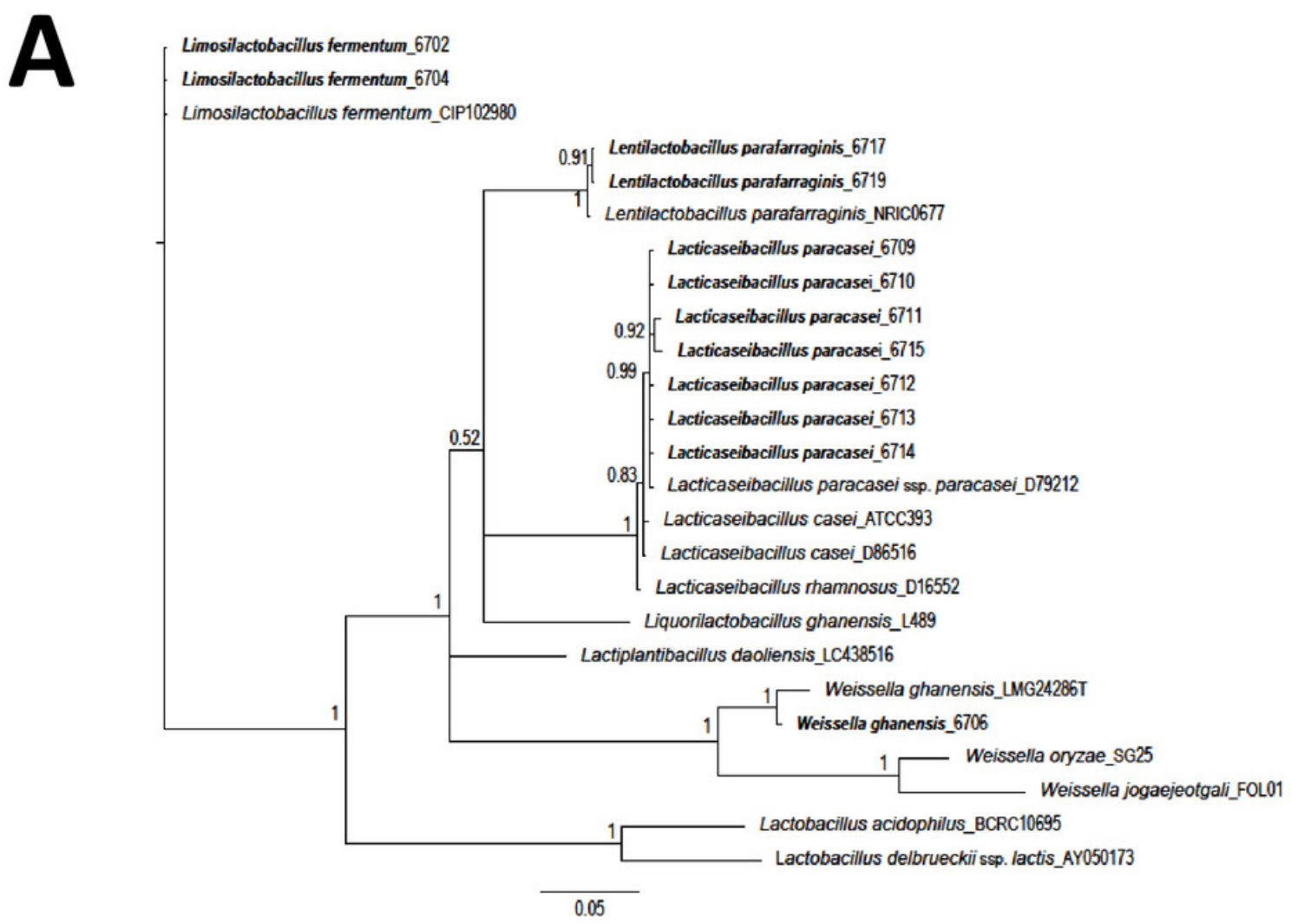

B

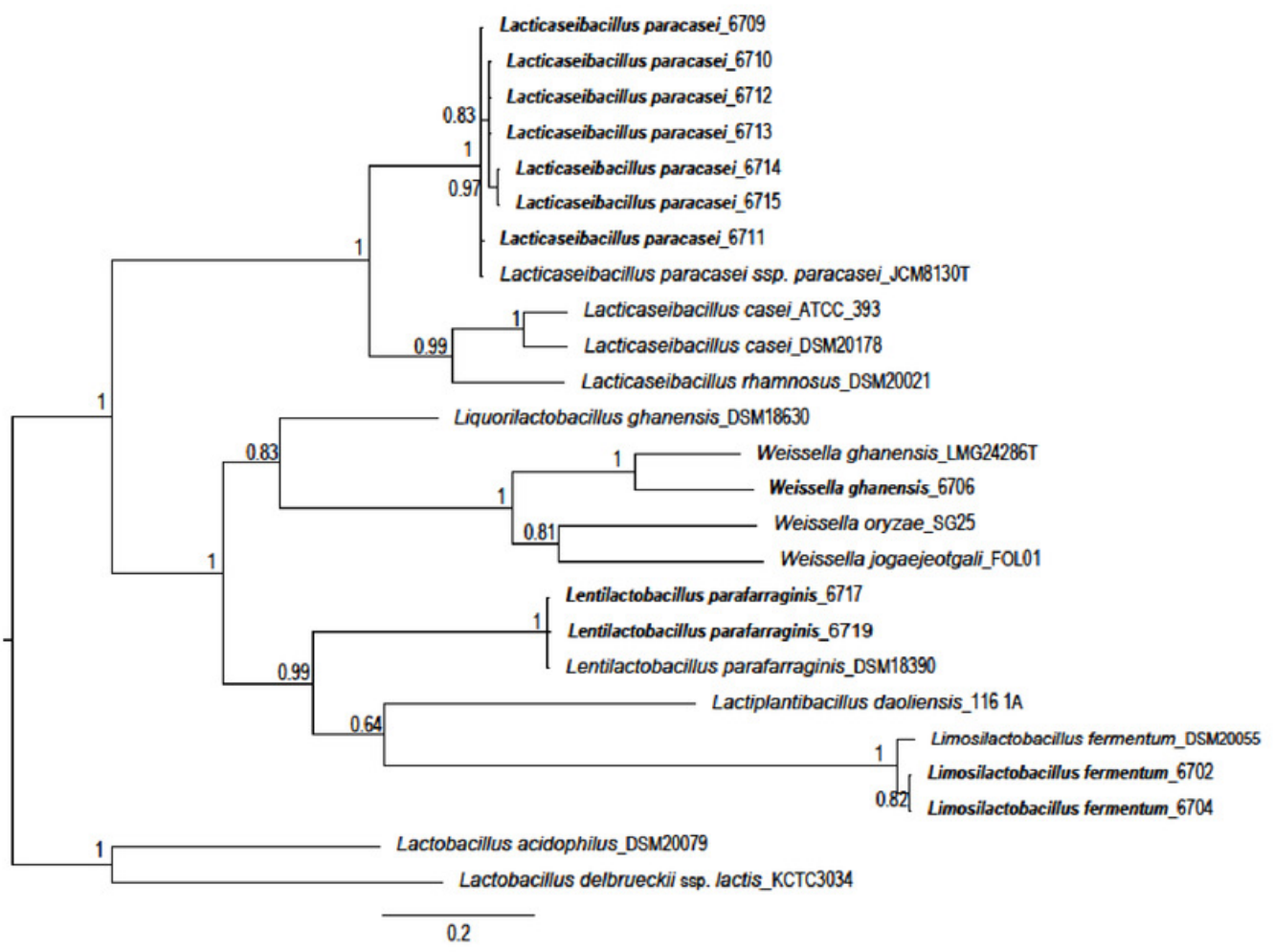


Figure 2

Cellular auto-aggregation ability of selected lactic acid bacteria (LAB) isolated from pineapple waste and comparison with L. casei ATCC 393.

Data are reported as mean \pm SD.

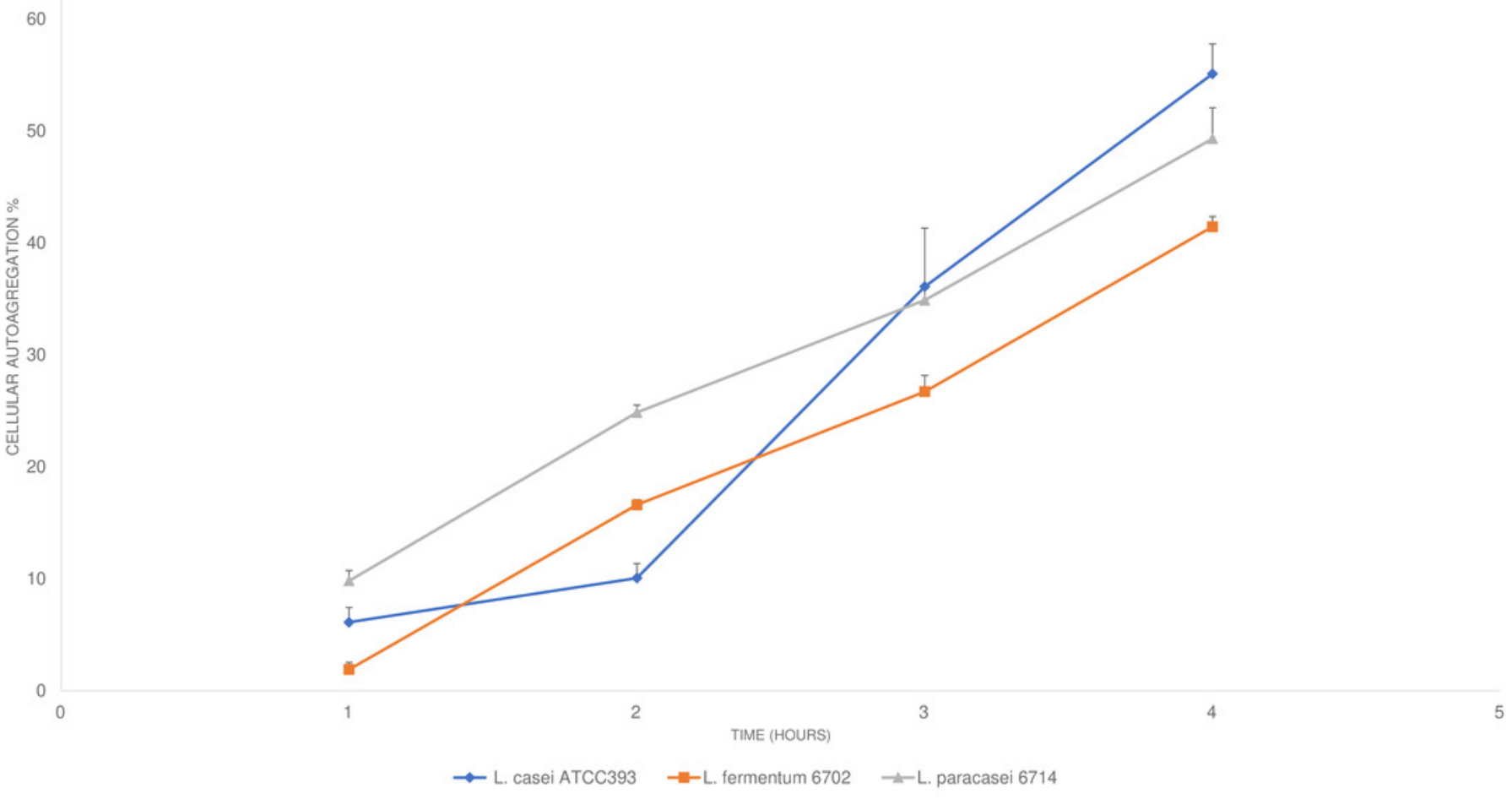

